\title{
Using Taguchi method for the optimization of processing variables to prepare porous scaffolds by combined melt mixing/particulate leaching
}

\author{
Roberto Scaffaro *, Fiorenza Sutera, Francesco Lopresti \\ Dipartimento di Ingegneria Civile, Ambientale, Aerospaziale, dei Materiali, Università di Palermo, Viale delle Scienze, 90128 Palermo, Italy
}

\section{H I G H L I G H T S}

- Polylactic acid porous scaffolds were successfully fabricated by combining melt mixing and particulate leaching.

- Mixing temperature and time are the most significant variable affecting mechanical properties of the scaffolds.

- Pores morphology was found to be affected by the kind of porogen salt (i.e. $\mathrm{NaCl}$ or $\mathrm{CaCl}_{2}$ ) and their dimension.

\section{G R A P H I C A L A B S T R A C T}

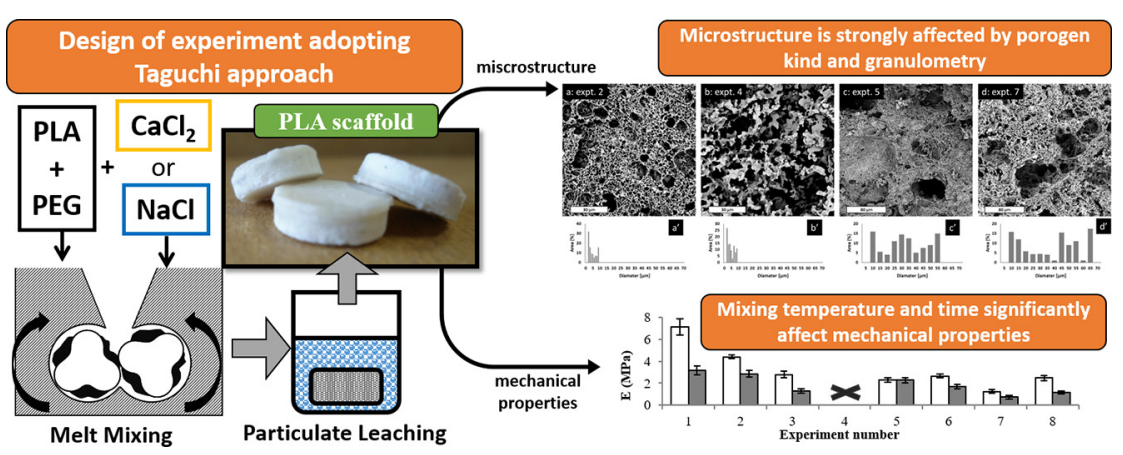

\begin{abstract}
A B S T R A C T
Synthetic biopolymers have made significant inroads into the development of devices for tissue regeneration. In this context, a challenge is the achievement of appropriate properties mimicking the natural extracellular matrix by fabricating scaffolds presenting mechanical properties, specific surface, porosity and pore interconnection adequate for the final application. This study involved a systematic procedure based on Taguchi method for parameters optimization of melt mixing/particulate leaching combined processes aiming to enhance the performance of the scaffolds. In particular, it was evaluated the effect of time and temperature of melt mixing of the poly(lactic acid) matrix with two water-soluble inorganic porogen agents (i.e. $\mathrm{NaCl}$ or $\mathrm{CaCl}_{2}$ ) with two different pore size and poly(ethylene glycol). Thereafter, the blends were compression molded and water-leached for different time and at different $\mathrm{pH}$. By adopting $\mathrm{L}_{8}$ Taguchi orthogonal array, seven control factors, each at two levels, were tested, and ANOVA was applied to find the statistically significant factors and the combination of their optimal levels. The results revealed that the mixing temperature had the highest effect on mechanical properties. Moreover, the internal architecture of the scaffolds was studied by morphological analysis, finding that it is affected by the kind of porogen salt and by mixing time.
\end{abstract}

(c) 2017 Elsevier Ltd. All rights reserved.

\footnotetext{
* Corresponding author.

E-mail address: roberto.scaffaro@unipa.it (R. Scaffaro).
}

\section{Introduction}

Over the past decades, one of the primary aims of tissue engineering was to develop scaffolds using biodegradable and biocompatible materials for repairing bone or tissue defects by a regenerative process [1]. Due to the complexity of the human body, mimicking the structural 
and biological function of native extracellular matrix (ECM) requires materials with manifold characteristics [2-5]. Biomaterials used for this aim are ceramics, bioglass, polymers, composites either of natural or synthetic origin and, rarely, metals [6,7]. The current challenge is to find an ideal device with the following characteristics: (i) mechanical behaviour matching that of replacement tissue; (ii) suitable surface that actively supports cell attachment, proliferation and differentiation to build up the new tissue; (iii) appropriate pore dimensions, porosity and interconnection between pores in order to allow the transport of cellular nutrients and metabolites [8-10]; (iv) biodegradation rate comparable with tissue regeneration rate and innocuous degradation products; (v) sterilizability to avoid toxic contamination [6]. Actually, the most promising materials are biopolymers, widely studied because they are nontoxic, biocompatible and possess desirable mechanical and physical properties [4,9-11]. Among biodegradable polymers of synthetic origin, poly(lactic acid) (PLA) has been extensively studied for several decades, thanks to its chemical-physical properties and easy processability [5,12-14]. One of the most efficient plasticizers for PLA is poly(ethylene glycol) (PEG) hydrophilic and biocompatible polymer $[13,15-18]$.

Since the above mentioned characteristics required for the scaffolds depend both on the polymer used and on the fabrication method [19], a wide variety of techniques have been developed to prepare scaffolds. Generally, those techniques can be divided into two groups: conventional and advanced [20]. Conventional techniques include combined melt mixing/particulate leaching $[5,13,17]$, thermally induced phase separation [21], combined solvent casting/particulate leaching (SC/PL) [22], combined high-pressure moulding/salt leaching [23], gas antisolvent [8]. Advanced techniques include, among the others, electrospinning $[9,24]$ and 3D printing [25]. Each of these techniques has strengths and weaknesses regarding resolution control and manufacturability; e.g., the widely used SC/PL method, on the one hand can effectively control the porosity by varying the amount and size of the pore former on the other hand it often uses toxic solvent [13].

Since each method present peculiar processing variables, considerable effort has been directed in searching the relationships between these parameters and the final performance of the scaffolds [19]. Therefore, determining the influence of the process conditions by appropriate optimization methods, such as statistical methods, represents a useful strategy to improve specific target properties. Among the statistical methods, Taguchi's method is a useful tool applied to investigate the effect of multiple variables on the observed properties. Recently, Taguchi's approach has been successfully applied in combination with the analysis of variance (ANOVA) for the optimization of process parameters of several processes, e.g. investigation of the optimal design of ternary activators activated slag [26], production of metal-composite overlap joints [27], fabrication of hybrid plastic-metal joints for medical device applications [28], synthesis of minimal-size ZnO nanoparticles [29], tribological analysis of composite fibers [30], electrochemical machining [31], plastic materials processing [32,33], steel manufacture [34,35], engineering ceramics [36,37]. Eddie et al. [38] used Taguchi method and ANOVA in the parametric study of the biopotential equation for breast tumour identification and, finally, Lin et al. [39] and Dar et al. [40] applied such method in conjunction with others statistical approach. Up to date, Vigneswari et al. have been the only ones who applied Taguchi method and ANOVA in the design of scaffolds for tissue engineering to investigate the effect the significant process parameters on the hydrophilicity of the scaffolds and to determine their optimal values [41].

For the first time, our study applied Taguchi's experimental design and ANOVA to maximize the mechanical properties of porous scaffolds fabricated by combining melt mixing and particulate leaching; this combined manufacturing method offers several advantages in terms of low cost production, industrial scalability and absence of dangerous/toxic solvents. The process was optimized by using Taguchi's orthogonal arrays (OAs), a simple and easy tool to investigate a large number of variables by performing a workable number of experiments.
More in detail, the effect of seven process variables, i.e. porogen salt, salt granulometry, mixing temperature and mixing time, leaching temperature, leaching time and leaching $\mathrm{pH}$, was investigated. This study analyses the effect of these parameters at two levels on the compressive Young's modulus in air and in phosphate buffered saline (PBS). The final goal is the determination of optimal values of the statistically significant processing variables, in order to maximize the compressive elastic modulus and to give immediate information and a precious tool to researchers for future studies. The results obtained have been validated by confirmation experiment.

\section{Theoretical background: statistical methods, Taguchi approach and ANOVA}

In 1920, for the first time the English statistician R. A. Fisher studied the effect of multiple variables simultaneously and developed a powerful statistical technique, the Design of Experiments (DOE) [42]. A design in which every setting of every factor (variable) appears with every setting of every other factor, identifying all possible combinations for the given set of factors, is a full factorial design $[43,44]$. The discrete values of the factors are named levels. If there are $\mathrm{k}$ factors, each at 2 levels, a full factorial design has $N=2^{\mathrm{k}}$ experiments [45]. However, since most industrial experiments usually involve a relevant number of factors, a full factorial design would often result in a too large number of experiments. The fractional factorial design reduces the number of experiments by selecting only a small set from all the possible experimental combinations. In this issue, to reduce the number of experiments to a practical level, Taguchi's approach inserts in the science of DOE by selecting only a small set of orthogonal arrays (OAs), from all possible experimental combinations, which includes all the independent combinations of the factors chosen [46].

Before beginning the experimental runs, Taguchi's approach decides the entire process, i.e. the factors, the levels, how run the tests, how analyse the results. These steps are in contrasts with the traditional techniques in which some initial ideas are tested, followed by other ideas and tests and so on. Taguchi's approach has consistency and reproducibility rarely found in any other statistical methods and it can be employed to obtain the best values of process variables, called optimal values in Taguchi's terminology, with the minimum number of investigations.

Analysis of variance (ANOVA) is the most common statistical method applied to results, in a factorial design of experiments, to determine which factors examined have most influence on the property of interest. The effect of one factor represents the variation of the response of interest of the process varying the levels of the same factor. ANOVA computes quantity called sum of squares, degree of freedom, variance and variance ratio and organizes in standard tabular format [47]. ANOVA uses a F-test to determine the statistically significant factors within the confidence interval examined. A more detailed explanation about ANOVA application is provided in the Supporting information (SI).

\section{Experimental}

\subsection{Design of experiments using the Taguchi approach}

The experiments were carried out with seven variables (factors) and two discrete values (levels) for each variable: type of porogen salt, salt granulometry, temperature and time of melt mixing, temperature, time and $\mathrm{pH}$ of leaching. Table 1 shows the factors selected and their levels.

It may be expected that the porogen salt factor may change the pore shape and therefore the microstructure of the scaffold, in addition to the leachability, while salt granulometry may dominates the pore size. It is reasonable to suppose that mixing temperature and time will vary the viscosity and the molecular weight of thermo-mechanically biodegradable PLA, which influence the mechanical properties. Finally, the factor 
Table 1

Parameters selected and their values at two different levels.

\begin{tabular}{llll}
\hline Code & Parameter & Level 1 & Level 2 \\
\hline A & Salt granulometry $(\mu \mathrm{m})$ & $0-45$ & $90-110$ \\
B & Mixing temperature $\left({ }^{\circ} \mathrm{C}\right)$ & 190 & 220 \\
C & Mixing time $($ seconds $)$ & 300 & 600 \\
D & Porogen salt & $\mathrm{NaCl}$ & $\mathrm{CaCl}_{2}$ \\
E & Leaching time (hours) & 5 & 8 \\
$\mathrm{~F}$ & Leaching temperature $\left({ }^{\circ} \mathrm{C}\right)$ & 50 & 70 \\
$\mathrm{G}$ & Leaching $\mathrm{pH}$ & 4.74 buffer & 7 no buffer \\
\hline
\end{tabular}

related to the leaching, i.e. time, temperature and $\mathrm{pH}$, will affect the efficiency of removing the porogen salt.

Table 2 presents the $\mathrm{L}_{8}$ Taguchi OA selected in this study with the assigned parameters. The table consists of seven columns, which were assigned the seven factors, and eight rows that define the eight trials conditions that have to be performed. Across the row, it is possible to read the discrete values, at the level 1 (low level) or 2 (high level) that must be assumed during the experiment.

\section{Materials and methods}

\subsection{Materials}

Poly(lactic acid) (PLA 2002D, $\mathrm{M}_{\mathrm{w}}=112,600 \mathrm{~g} / \mathrm{mol}$, density $\rho=$ $1.24 \mathrm{~g} / \mathrm{cm}^{3}$ [48]) was purchased from NatureWorks ${ }^{\circledR}$. Poly(ethylene glycol) (PEG, $\mathrm{M}_{\mathrm{w}}=2000 \mathrm{~g} / \mathrm{mol}, \rho=1.12 \mathrm{~g} / \mathrm{cm}^{3}$ ), sodium chloride $\left(\mathrm{NaCl}\right.$, purity $\left.>99 \%, \rho=2.16 \mathrm{~g} / \mathrm{cm}^{3}\right)$ and calcium chloride $\left(\mathrm{CaCl}_{2}\right.$, purity $>93 \%, \rho=2.15 \mathrm{~g} / \mathrm{cm}^{3}$ ) were purchased by Sigma-Aldrich.

In this work, $\mathrm{NaCl}$ and $\mathrm{CaCl}_{2}$ were first ground and sieved to obtain two size ranges in order to fabricate scaffolds with two different pore dimensions, i.e. $0-45 \mu \mathrm{m}$ and $90-110 \mu \mathrm{m}$. Before processing, both PLA and the salts were dried in a vacuum oven at $90^{\circ} \mathrm{C}$ for $16 \mathrm{~h}$ to prevent macromolecules hydrolytic scission and particles re-aggregation during processing.

\subsection{Scaffolds fabrication}

Porous scaffolds have been manufactured by melt mixing as described in our previous works $[10,49]$. In brief, PLA/PEG/salt, with formulation 12/3/85 wt\%, were fed to a batch mixer (Brabender PLE-330) and processed at the temperature and for the period of time of the specific running experiment, as reported in Table 2 . The blends were compression molded in a Carver laboratory press at $210^{\circ} \mathrm{C}$ and 180 bar in an appropriate cylindrical mold with a diameter of $10 \mathrm{~mm}$ and a height of $3 \mathrm{~mm}$.

The final step is the selective leaching of the porogen agents of the scaffolds (salt and PEG) in demineralized water under the specific conditions of temperature, time and $\mathrm{pH}$ depending of the running experiment. The resulting porous structures were let to dry for $24 \mathrm{~h}$ at room temperature. Figs. 1a-b show the samples before leaching and after leaching and drying.

\subsection{Characterizations}

\subsubsection{Scanning Electron Microscopy (SEM)}

The morphology of the scaffolds were evaluated by scanning electron microscopy (Quanta 200 ESEM, FEI) equipped with EDX probe. The samples were fractured in liquid nitrogen and then sputter-coated with a thin layer of gold (Sputtering Scancoat Six, Edwards) in order to avoid electrostatic discharge during the test.

\subsubsection{Pore Size Distribution (PSD)}

Pore size analyses were carried out using a MATLAB (MathWorks Inc., MA, USA) based software previously described [49]. The custommade software is able to accomplish the segmentation of images containing pores of any geometry in a semi-automatic way. It converts the digital images into binary form and then calculates the pores area distribution (PAD). The software reports the percentage of the total area occupied by the pores having diameters in a given interval. PAD were calculated in different seven region of the scaffolds. A minimum of 7 spots for each experiment were analyzed and representative data were shown.

\subsubsection{Torque measurements}

During the melt processing step, the mixing torque was monitored versus the time to obtain qualitative indications of melt viscosity.

\subsubsection{Mechanical properties}

Compression tests on the scaffolds were performed in two different mediums, air and phosphate buffered saline (PBS), using an universal testing machine (Instron model 3365). The tests in air were carried out at room temperature while those in PBS were carried out at $T=$ $37^{\circ} \mathrm{C}$ by using BioPuls Temperature Controlled Bath (Norwood, MA), $\mathrm{pH}=7.4$. In order to prepare samples to measurements in BioPuls Bath, the pores of the scaffolds were filled with PBS in a vacuum flask for $5 \mathrm{~min}$ to let PBS to fill the inner pores. Thereafter, the scaffolds were left in PBS at $37^{\circ} \mathrm{C}$ for 15 min to let the achievement of the temperature test throughout the structure. The samples (3:10 height-diameter ratio) were tested under deformation control with a constant crosshead speed of $1 \mathrm{~mm} / \mathrm{min}$. A minimum of 7 specimens were averaged for each experiment.

\subsection{Statistical analyses}

Analysis of variance (ANOVA) was applied for investigating the percentage contribution of the individual parameters on compressive Young's modulus in air and in PBS. ANOVA computes quantity called sum of squares (SS), degree of freedom (DOF), variance (V) and variance ratio, organizes in standard tabular format [47] and uses a F-test to determine the statistically significant factors within the confidence interval examined (see S2 section in SI).

According to Taguchi method, after identifying the optimal level of each process parameter, a confirmation test was carried out and statistical analyses of the data were performed by using the GraphPad Prism version 6 software (GraphPad Software Inc., La Jolla, CA, USA). Significant differences among mean values were determined by the means

Table 2

Taguchi orthogonal array $L_{8}$ of the experimental runs.

\begin{tabular}{|c|c|c|c|c|c|c|c|}
\hline Expt. no. & A Salt granulometry $(\mu \mathrm{m})$ & B Mixing temperature $\left({ }^{\circ} \mathrm{C}\right)$ & C Mixing time (s) & D Porogen salt & E Leaching time $(\mathrm{h})$ & F Leaching temperature $\left({ }^{\circ} \mathrm{C}\right)$ & G Leaching $\mathrm{pH}$ \\
\hline 1 & $0-45$ & 190 & 300 & $\mathrm{NaCl}$ & 5 & 50 & 4.74 \\
\hline 2 & $0-45$ & 190 & 300 & $\mathrm{CaCl}_{2}$ & 8 & 70 & Neutral \\
\hline 3 & $0-45$ & 220 & 600 & $\mathrm{NaCl}$ & 5 & 70 & Neutral \\
\hline 4 & $0-45$ & 220 & 600 & $\mathrm{CaCl}_{2}$ & 8 & 50 & 4.74 \\
\hline 5 & $90-110$ & 190 & 600 & $\mathrm{CaCl}_{2}$ & 5 & 50 & Neutral \\
\hline 6 & $90-110$ & 190 & 600 & $\mathrm{NaCl}$ & 8 & 70 & 4.74 \\
\hline 7 & $90-110$ & 220 & 300 & $\mathrm{CaCl}_{2}$ & 5 & 70 & 4.74 \\
\hline 8 & $90-110$ & 220 & 300 & $\mathrm{NaCl}$ & 8 & 50 & Neutral \\
\hline
\end{tabular}



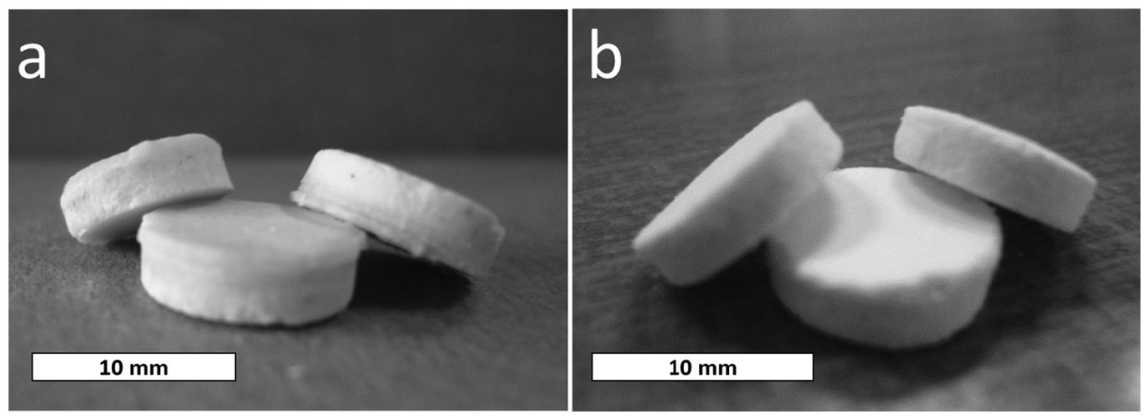

Fig. 1. (a) Example of scaffolds before the leaching and (b) after the leaching and the drying for $24 \mathrm{~h}$ at room temperature.

of ANOVA and by Tukey's Honestly Significant Difference (HSD) post hoc test for multiple comparisons.

In this work, the statistical analyses were carried out for a level of confidence of $95 \%$.

\section{Results and discussion}

\subsection{Morphological analysis of scaffolds}

The morphology of the scaffolds was observed to investigate the effect of salt type and particles size on the internal porous architecture. Since the pores morphology strongly depends on the type of salt involved in the experiment, the SEM images related to $\mathrm{NaCl}$ salt, i.e. experiments no. $1,3,6,8$, and the SEM images related to $\mathrm{CaCl}_{2}$ salt, i.e. experiments no. $2,4,5,7$, will be shown and discussed separately.

\subsection{Experiments with $\mathrm{NaCl}$ as porogen salt (expts. no. 1, 3, 6, 8)}

Figs. 2a-d show the SEM images of the porous architecture of the scaffolds obtained by leaching $\mathrm{NaCl}$, while Figs. 2a'-d' show their corresponding PAD. In particular, Fig. 2a displays the morphological structure of the scaffolds manufactured under the experimental conditions no. 1 which keep all the factors at the lowest level. The macro-pores, resulting by $\mathrm{NaCl}$ solubilization, are highly interconnected due to the micro-pores in the walls, formed during PEG solvation $[4,13,49]$. The presence of these micro-pores in the structure is crucial because they drive the water deeply in the core of the structure ensuring complete leaching of the scaffold and allowing the passage of cell nutrients after implantation.
SEM analysis showed no evidence of the presence of residual $\mathrm{NaCl}$ particles as confirmed by EDX analysis carried out on all the related materials. In fact, the EDX carried out on the experiments with $\mathrm{NaCl}$ as porogen salt revealed the presence of only three elements i.e. $\mathrm{O}$ (in the range 64-66 atomic \%), C (in the range 32-34 atomic \%) and $\mathrm{Au}$ (in the range 2.8-3.2 atomic \%) due to the sputter-coating with gold.

The presence of PEG, partially miscible with PLA, induced roughness to the pore walls (Fig. 2a) also according to previous findings [13,50]. Indeed, it is known that the plasticizing effect of PEG increases chain mobility and also acts as nucleating agent accelerating the creation of crystalline domains; the formation of spherulites with different size, morphologies and distribution in PLA/PEG blends leads to surface roughness [15]. The PAD of this system, shown in Fig. 2a', presents a bimodal behaviour with two peaks at $20 \mu \mathrm{m}$ and $40 \mu \mathrm{m}$.

Fig. 2b shows the morphology of the scaffolds prepared under the following experimental condition (expt. no. 3): salt granulometry 0-45 $\mu \mathrm{m}$, mixing temperature $220^{\circ} \mathrm{C}$, mixing time $600 \mathrm{~s}$, porogen salt $\mathrm{NaCl}$, leaching time $5 \mathrm{~h}$, leaching temperature $70^{\circ} \mathrm{C}$ and neutral $\mathrm{pH}$. The presence of a higher number of pores smaller than $10 \mu \mathrm{m}$ (Fig. 2b') can be likely associated to the longer mixing time that increased the $\mathrm{NaCl}$ breaking. The leaching condition seems not to affect the shape of the pores.

In Fig. $2 c$ the size range of the salt leached is $90-110 \mu \mathrm{m}$. The pore dimensions has a bimodal behaviour (Fig. 2c') with a peak at about $50 \mu \mathrm{m}$ and another corresponding to the salt granulometry. The walls of the internal structure appear rough, likely due to leached PEG incorporated in the blend, as it was also found in the other experimental runs. However, compared to the previous cases, pore shape is more similar to $\mathrm{NaCl}$ crystals shape. This result can be justified by the larger dimensional range of
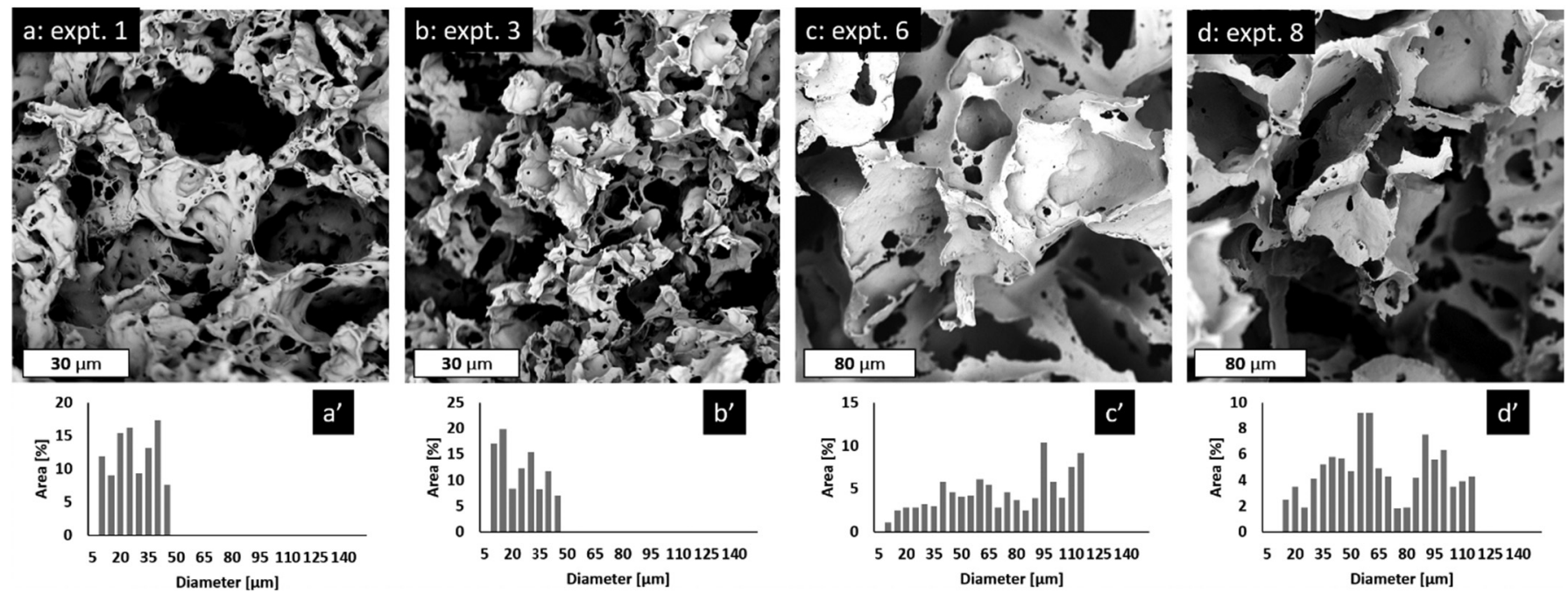

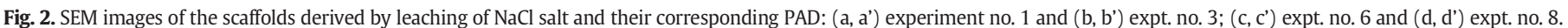


the salt particles that produces a lower interfacial area and, as a consequence, promotes a more efficient PLA wrapping of the $\mathrm{NaCl}$ particles. It is evident the effectiveness of the leaching process, in agreement with the strong leaching conditions, $T=70^{\circ} \mathrm{C}$ and $t=8 \mathrm{~h}$.

The morphological structure of the scaffolds prepared in run no. 8 i.e. $\mathrm{NaCl}$ as porogen salt with granulometry $90-110 \mu \mathrm{m}$, mixed at $220{ }^{\circ} \mathrm{C}$ for $300 \mathrm{~s}$, and leached $8 \mathrm{~h}$ at $50{ }^{\circ} \mathrm{C}$ and neutral $\mathrm{pH}$ - is showed in Fig. 2d. The PAD, in Fig. 2d', is similar to the PAD in Fig. $2 c^{\prime}$ (expt. no. 6) but the peak at $50 \mu \mathrm{m}$ is higher than that at $100 \mu \mathrm{m}$. Again, this result highlights the effect of the mixing time on the PAD, i.e. higher mixing time increases $\mathrm{NaCl}$ fracture. The leaching variables seem to not to affect the morphology of the pores.

\subsection{Experiments with $\mathrm{CaCl}_{2}$ as porogen salt (expts. no. 2, 4, 5, 7)}

Figs. 3a-d and Figs. 3a'-d' report the morphologies and their corresponding PAD of the scaffolds manufactured with calcium chloride as porogen salt. They are deeply different compared to those deriving from sodium chloride. Fig. 3a shows the uniform and rounded pore shape of the scaffold obtained in run no. $2, \mathrm{CaCl}_{2}$ particles diameter 0-45 $\mu \mathrm{m}$, temperature and melt mixing time respectively $190{ }^{\circ} \mathrm{C}$ and $300 \mathrm{~s}$, temperature and time of leaching equal to $70^{\circ} \mathrm{C}$ and $8 \mathrm{~h}$, and neutral $\mathrm{pH}$. The walls are not indented, as found in the case of $\mathrm{NaCl}$, and the small thickness allow forming a continuous structure surrounding the pores, despite the higher superficial area of the salt particles due to smaller granulometry. These results may derive from the different shape of $\mathrm{CaCl}_{2}$ crystals and their interaction with the matrix, if compared to $\mathrm{NaCl}$ crystals. The PAD in Fig. 3a' shows a bimodal pore distribution with high number of micropores and a little peak around $10 \mu \mathrm{m}$. Fig. 3b displays the SEM image of the scaffolds fabricated during expt. no. 4 , that is by using $\mathrm{CaCl}_{2}$ salt with size range $0-45 \mu \mathrm{m}$, by mixing the material for 600 s at $220^{\circ} \mathrm{C}$ and by leaching the scaffolds $8 \mathrm{~h}$ at $50^{\circ} \mathrm{C}$ and $\mathrm{pH} 4.74$. The structure is highly porous and interconnected with rough walls and a bimodal PAD very similar to that of the exp. no. 2, as highlighted in Fig. 2b'. In Fig. 3c, it is reported the morphology of scaffolds prepared using particles diameter $90-110 \mu \mathrm{m}$, mixed at $190^{\circ} \mathrm{C}$ for $600 \mathrm{~s}$ and leached at $50{ }^{\circ} \mathrm{C}, 5 \mathrm{~h}$ at neutral pH (variable set no. 5). The morphology is similar to that of the scaffolds prepared in expt. no. 2 except for pore dimensions, that present three PAD peaks at about $10 \mu \mathrm{m}$, $35 \mu \mathrm{m}$ and $45 \mu \mathrm{m}$ (Fig. 3c'). Finally, Fig. $3 \mathrm{~d}$ exhibits the internal structure of the scaffolds prepared during the experiment no. 7 , with the granulometry $90-110 \mu \mathrm{m}$, the mixing temperature of $220^{\circ} \mathrm{C}$ for $300 \mathrm{~s}$ and leached at $70^{\circ} \mathrm{C}, 5 \mathrm{~h}, \mathrm{pH}$ value 4.74 . The three-modal PAD behaviour (Fig. 3d') is very similar to that found in expt. no. 5, being equal the size range of the salt particles. All the structures are highly porous and interconnected. The morphological analysis clearly revealed that the use of $\mathrm{CaCl}_{2}$ as porogen agent makes difficult the control of internal architecture of the scaffold. Indeed, although expts. no. 5 and no. 7 were carried out with salt granulometry in the range $90-110 \mu \mathrm{m}$, the resulting pores dimension is smaller. This phenomenon should be due to the breakage of $\mathrm{CaCl}_{2}$ particles during the melt mixing, easier if compared to $\mathrm{NaCl}$. The breakage of the $\mathrm{CaCl}_{2}$ particles can be also considered the reason to the uneven distribution of pores size showed by the PAD. Even in this case, SEM analysis showed no evidence of the presence of residual $\mathrm{CaCl}_{2}$ particles: the EDX carried out on the experiments with $\mathrm{CaCl}_{2}$ as porogen salt revealed the presence of oxygen, carbon and gold in the same atomic \% range of the $\mathrm{NaCl}$ experiments. The leaching time and temperature seem to not to affect the morphology of the pores.

\subsection{Viscosity measurements of the blends}

Qualitative indications of melt viscosity and viscosity-temperature dependence can be obtained by using Brabender torque-rheometer [51]. Therefore, during the melt mixing operation the torque values were collected and reported as a function of time to indirectly monitor the variation of viscosity of the blends. The torque offered by the blends depends both on kind and on granulometry of the salt and on mixing temperature. Fig. 4 shows the torque values of the blends incorporating sodium chloride as porogen salt. It is worth noting that the torque of the blends processed at $220^{\circ} \mathrm{C}$ (expts. no. 3 and no.8) is lower than that observed for the blends processed at $190{ }^{\circ} \mathrm{C}$ (expts. no. 1 and no. 6). This behaviour is due to the improvement of the mobility of the polymer chains and to the decrease of the resistance between the melt layers at higher temperature [52], related to the decreasing of the melt viscosity with increasing temperature.

After an initial steep reduction, the torque slowly decreased due to the melting of the polymer matrix. Thereafter, a steady state is reached and this stabilization is remarkable for longer time, i.e. $600 \mathrm{~s}$, and less evident for shorter time, i.e. $300 \mathrm{~s}$.

The blends containing $\mathrm{CaCl}_{2}$ show torque values higher than those of the blends with $\mathrm{NaCl}$, particularly in the early moments of the mixing (Fig. 5). This behaviour might be due to the easier breakage of the crystals that produces a larger surface area. Indeed, from PAD analysis of the expts. no. 2 and no. 4 (Figs. 3a'-b'), salt granulometry 0-45 $\mu \mathrm{m}$, it can be observed high amount of the pores in the dimensional range 1-10 $\mu \mathrm{m}$ and few pores in the dimensional range 10-45 $\mu \mathrm{m}$. Likewise, for the $90-110 \mu \mathrm{m}$ size range, most of pores belongs to a smaller dimensional range, probably due to the breakage of salt particles during mixing.

In Fig. 5, the curves of the systems mixed at $190^{\circ} \mathrm{C}$, namely expts. no. 2 and no. 5 , show values of torque higher than the systems no. 4 and no.
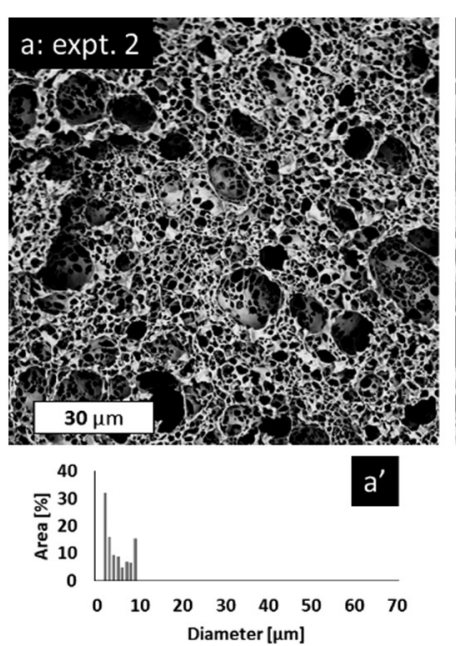
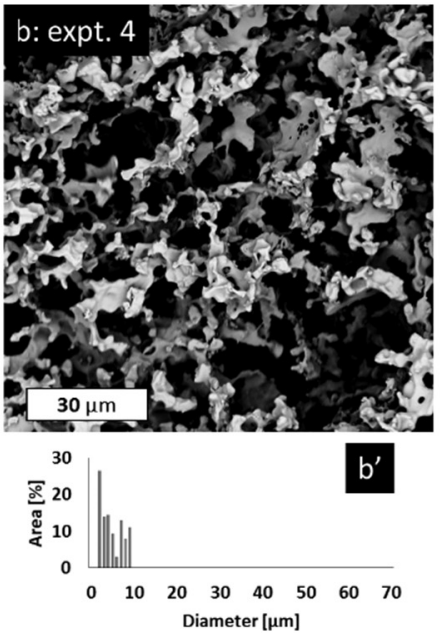
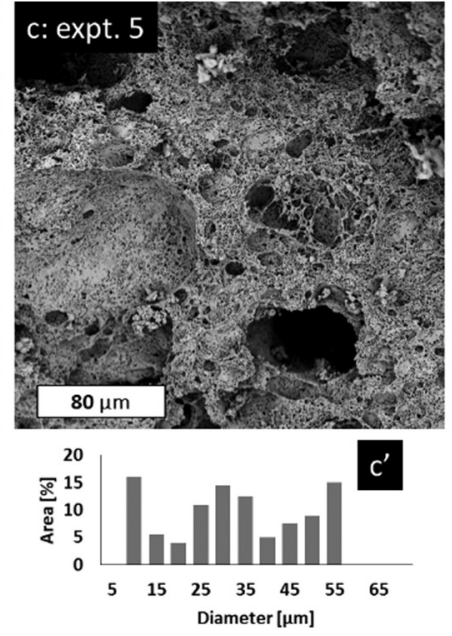

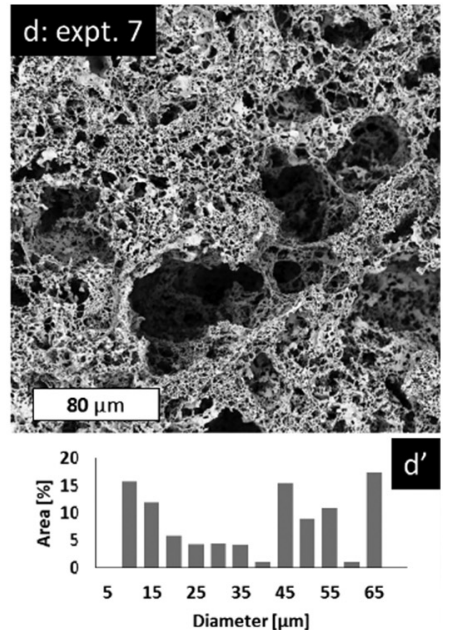

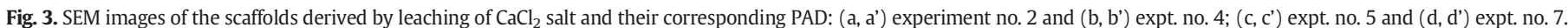




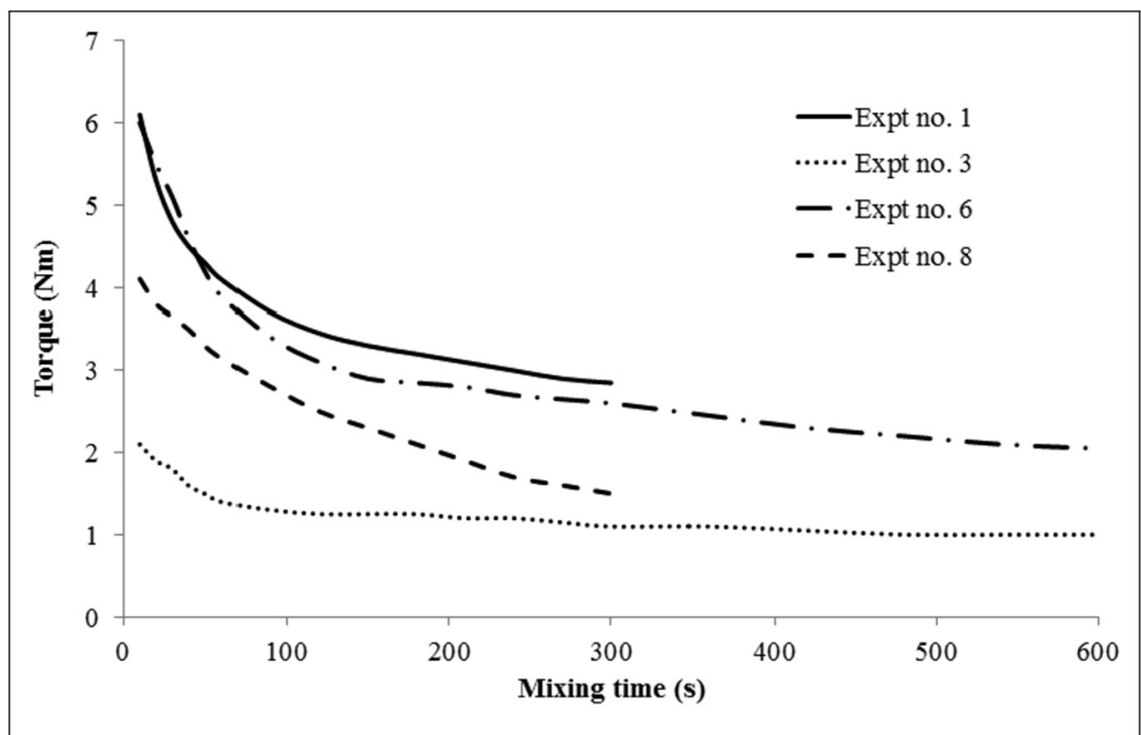

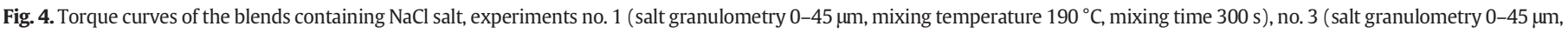

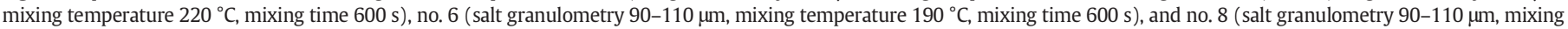
temperature $220^{\circ} \mathrm{C}$, mixing time $300 \mathrm{~s}$ ).

7 mixed at $220^{\circ} \mathrm{C}$, in accordance with the decrease of viscosity with temperature. Being temperature the same, the torque of the blend no. 2 (size range $0-45 \mu \mathrm{m}$ ) is higher than that of the blend no. 5 (size range $90-110 \mu \mathrm{m}$ ) and the torque of the blend no. 4 (size range $0-45 \mu \mathrm{m}$ ) and is higher than that of the blend no. 7 (size range $90-110 \mu \mathrm{m})$. At the same temperature conditions, the torque depends by the dimensional range of the particles: by decreasing the diameter of the particles, the torque increases because of the higher interfacial area and subsequent larger interaction between $\mathrm{CaCl}_{2}$ salt and polymer matrix.

As in the case of blends with $\mathrm{NaCl}$, at the beginning of the mixing time, the values of torque quickly decrease because of polymer matrix melting that causes the reduction of viscosity, afterwards the trend is almost constant (Fig. 5).

\subsection{Effect of the process variables on mechanical properties}

As already marked in this study, the aim of the optimization of process parameters is the maximization of the compressive Young's modulus.

The compressive mechanical tests were carried out both in air at ambient temperature and in PBS at $37^{\circ} \mathrm{C}$ to simulate wet conditions.

Fig. 6 displays nominal stress-strain curves $(\sigma-\varepsilon)$ of the scaffolds. After the initial elastic deformation (Fig. 6-inset), likely related to the bending of the walls of the pores [13], there is a transition zone that indicates the beginning of the permanent plastic deformation (Fig. 6inset) $[13,53]$. The final region of the stress-strain curve monolithically increases, indicating the typical plastic deformation of the thermoplastic polymers, which may be associated with the densification of the

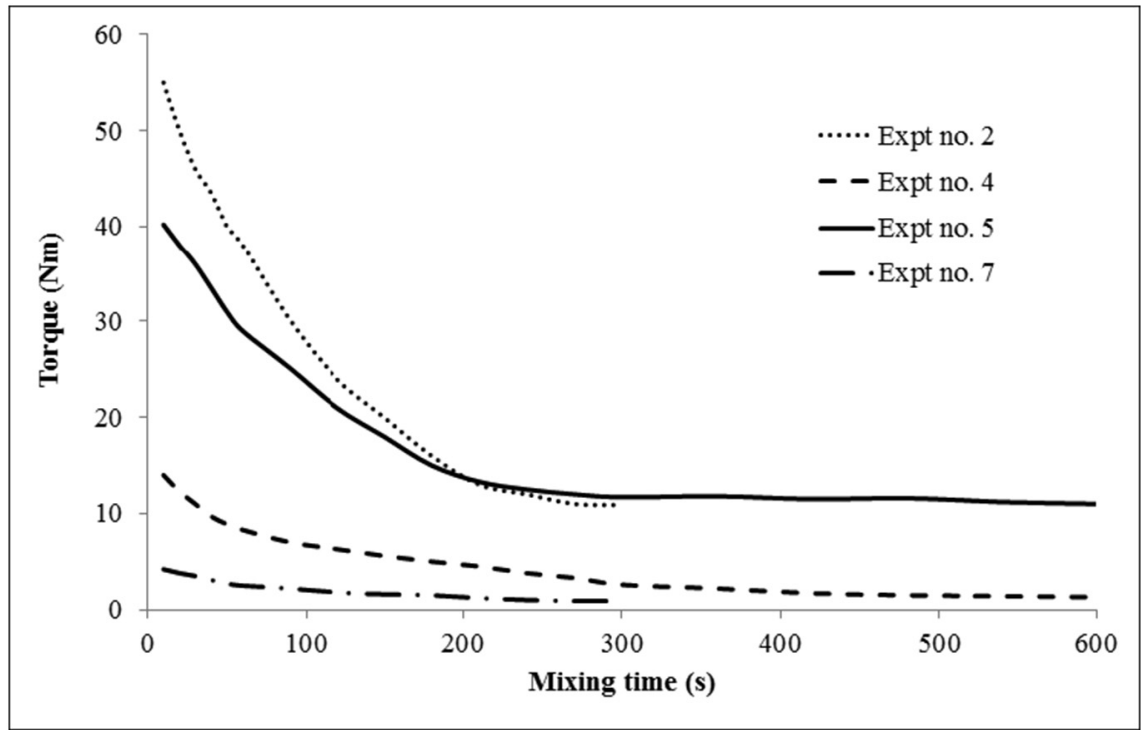

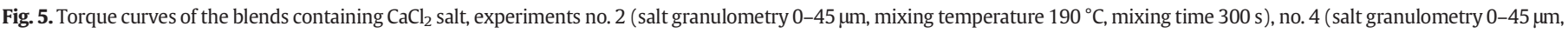

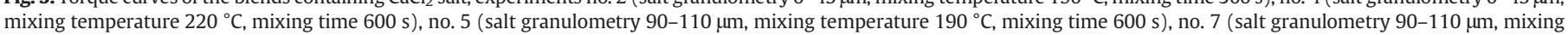
temperature $220^{\circ} \mathrm{C}$, mixing time $300 \mathrm{~s}$ ). 


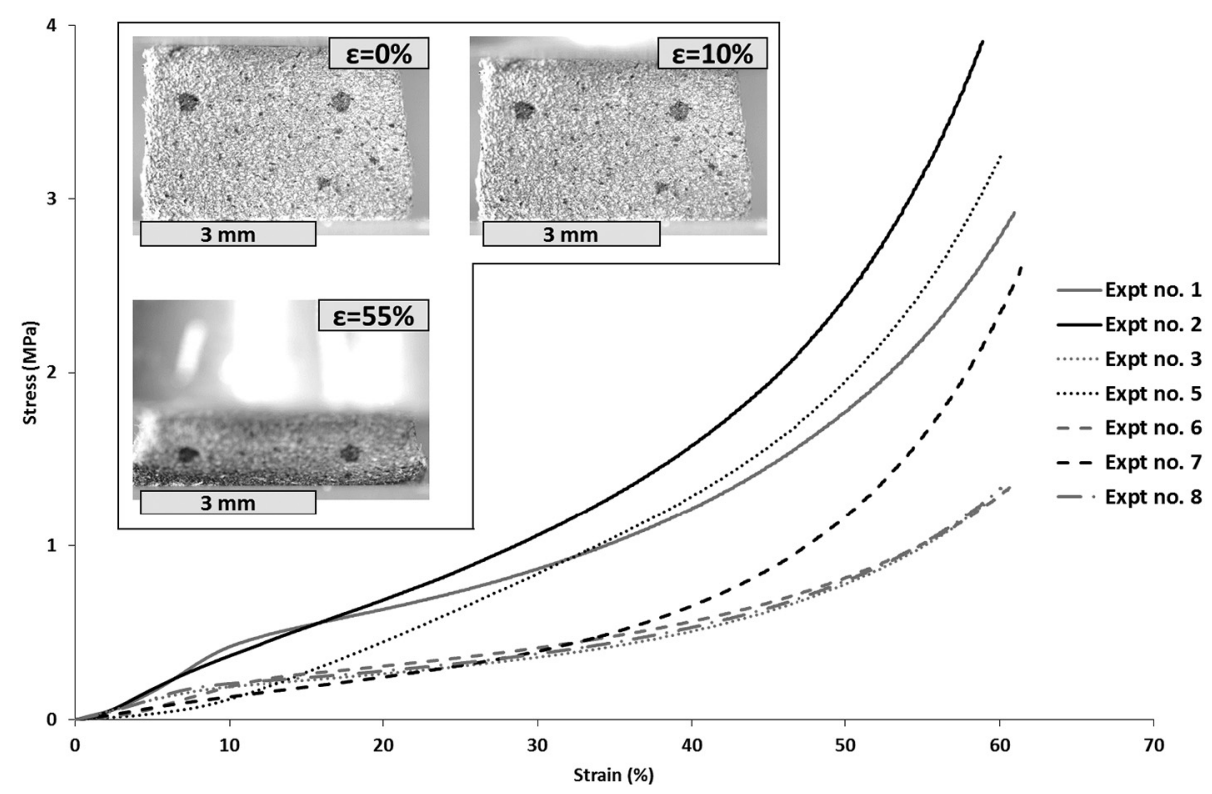

Fig. 6. Compressive stress-strain curves of the scaffolds. Inset: pictures of the scaffold (expt. no. 8) during compression at different strain percentage ( $\varepsilon$ ).

internal architecture of the sample (Fig. 6-inset) [13]. The shape of the stress-strain curves of the scaffolds tested in PBS is the same, even if, of course, with values of lower magnitude.

Fig. 7 reports the mean values of the compressive Young's modulus in air and in PBS, calculated as the slope of the linear stretch in the stress-strain curves, for the scaffolds of all the experimental runs. The diagram does not show the values of the expt. no. 4 because the scaffolds crumbled during leaching. This phenomenon might be imputed to the previous degradation of the material during melt mixing operation under the hardest conditions, i.e. $T=220^{\circ} \mathrm{C}$ and $t=600 \mathrm{~s}$.

The data in Fig. 7 were used for F-test calculation and Table 3 shows the results of pooled ANOVA for the dry elastic modulus. At first, column $G$ was associated with the estimate of the error due to its lower SS value. In these calculations, no factor was found to be statistically significant. Therefore, by pooling up and by merging $\mathrm{G}$ and $\mathrm{F}$ column effects, the factors A-E were found to be statistically significant at a level of confidence of $95 \%$. The last column of Table 3 shows the percentage contribution of each factor on the total variation of the elastic modulus, that is the degree of influence on the result.
In Fig. 7, the highest elastic modulus is observed for the of the experiment no. 1, followed by expt. no. 2 . These blends were melt mixed at $190{ }^{\circ} \mathrm{C}$ for $10 \mathrm{~min}$ which are the optimal levels of the first two factors statistically significant revealed by the analysis of variance. The following statistically significant factors, in order of significance, are: type of salt, size range and leaching time. These results can be likely associated to the degradation of the polymer chains induced by melt mixing. In fact, it is well established that PLA is susceptible to thermodegradation during melt processing operations [54]. The use of $\mathrm{NaCl}$ salt gives more uniform internal structure while smaller pore size leads to more homogeneous mass distribution of PLA in the scaffold [55] and a greater number of points of contacts, so that the elastic modulus of the devices is higher. The lower leaching time, level 1 of the factor E, allows the scaffolds to be exposed at the thermal stress of leaching for a shorter time, however, it is the least influential factor.

The tests carried out in wet condition present values of the elastic modulus lower than the corresponding in dry (Fig. 7), therefore the elastic characteristic of the materials immersed in PBS decreases, except for the expt. no. 5 that presents a values almost constant.

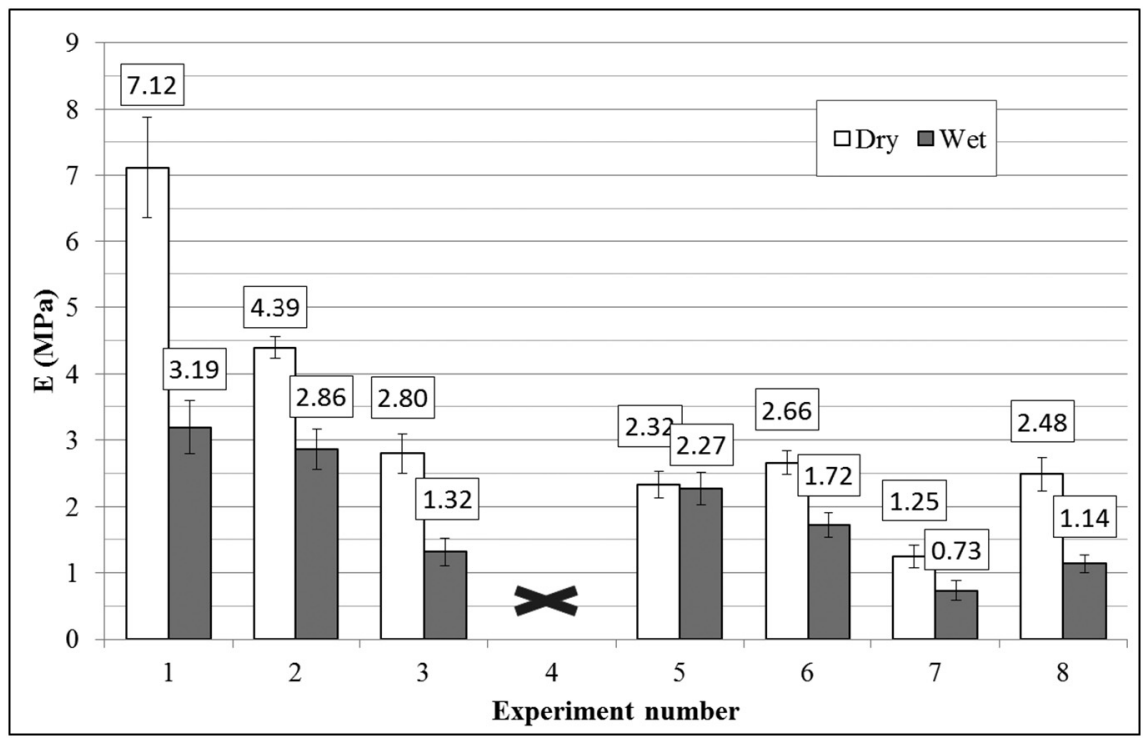

Fig. 7. Compressive Young's modulus of the scaffolds in dry and wet environment, for all the experimental runs. 
Table 3

ANOVA for Young's modulus in air.

\begin{tabular}{llllll}
\hline Source & SS & DOF & $V$ & $\begin{array}{l}\mathrm{F}_{\text {calc }}(\mathrm{e} \\
\text { pooled })\end{array}$ & $\mathrm{P}(\%)$ \\
\hline $\mathrm{A}$ & 3.920 & 1 & 3.920 & $39.35^{\mathrm{b}}$ & 12.35 \\
$\mathrm{~B}$ & 12.400 & 1 & 12.400 & $124.47^{\mathrm{b}}$ & 39.07 \\
$\mathrm{C}$ & 6.956 & 1 & 6.956 & $69.83^{\mathrm{b}}$ & 21.92 \\
$\mathrm{D}$ & 6.301 & 1 & 6.301 & $63.25^{\mathrm{b}}$ & 19.85 \\
$\mathrm{E}$ & 1.960 & 1 & 1.960 & $19.68^{\mathrm{b}}$ & 6.18 \\
$\mathrm{~F}^{\mathrm{a}}$ & 0.084 & 1 & 0.084 & & 0.26 \\
$\mathrm{G}^{\mathrm{a}}$ & 0.115 & 1 & 0.115 & & 0.36 \\
Tot & 31.737 & 7 & & & \\
e pooled & 0.199 & 2 & 0.100 & & \\
\hline
\end{tabular}

SS Sum of squares, DOF Degree of freedom, $V$ Variance, $\mathrm{F}_{\text {calc }} \mathrm{F}$ value calculated in $\mathrm{F}$ test, $\mathrm{P}$ $(\%)=\mathrm{SS}_{\mathrm{Tot}} / \mathrm{SS}_{\mathrm{i}}$ Percent contribution.

a Factors merged in e pooled.

b Significant at $95 \%$ confidence level.

Table 4 shows the analysis of variance performed for the wet elastic modulus. At $95 \%$ confidence level, by considering the factor $\mathrm{F}$ for the evaluation of the error, all the factors were found to be statistically significant. In this case, it was not necessary to apply pooling up method.

Table 5 displays the significant factors affecting Young's modulus in air and in PBS, in order of contribution, and their optimal values among those investigated. It is interesting to note that in the case of wet elastic modulus, unlike the dry elastic modulus, the $\mathrm{pH}$ of leaching takes statistically significance overcoming the effects of time leaching and salt granulometry.

\section{Confirmation test}

Confirmation test with the optimal levels of the significant parameters was carried out in order to verify the effectiveness of the results in Taguchi's design approach [47]. The optimal values were set for the significant factors while the no significant factors were set at economic levels. Seven confirmation experiments were conducted and the average of the results is equal to 7.34 and 3.26 for $E_{d r y}$ and $E_{\text {wet }}$ respectively. According Tukey's HSD post hoc test, the values did not show statistically significant difference if compared with the optimum performance estimated by the expt. no. 2 .

\section{Conclusions}

Processing parameters generally have a great impact on the mechanical properties of polymer based systems. The Taguchi method was applied to investigate the effects of seven process parameters on the properties of PLA-based porous scaffolds for tissue engineering prepared by combined melt mixing and particulate leaching.

The results obtained in this study indicate that the most statistically significant factors affecting the mechanical properties are temperature and time of mixing, kind of porogen salt, followed by salt granulometry

Table 4

ANOVA for Young's modulus in PBS.

\begin{tabular}{llllll}
\hline Source & SS & DOF & $V$ & $\begin{array}{l}\mathrm{F}_{\text {calc }} \\
(e=F)\end{array}$ & $\mathrm{P}(\%)$ \\
\hline $\mathrm{A}$ & 0.285 & 1 & 0.285 & $2533^{\mathrm{a}}$ & 3.49 \\
$\mathrm{~B}$ & 5.865 & 1 & 5.865 & $52,136^{\mathrm{a}}$ & 71.85 \\
$\mathrm{C}$ & 0.852 & 1 & 0.852 & $7569^{\mathrm{a}}$ & 10.43 \\
$\mathrm{D}$ & 0.285 & 1 & 0.285 & $2533^{\mathrm{a}}$ & 3.49 \\
$\mathrm{E}$ & 0.401 & 1 & 0.401 & $3560^{\mathrm{a}}$ & 4.91 \\
$\mathrm{~F}$ & $0.112 \times 10^{-3}$ & 1 & $0.112 \times 10^{-3}$ & & 0.00 \\
G & 0.475 & 1 & 0.475 & $4225^{\mathrm{a}}$ & 5.82 \\
Tot & 8.163 & 7 & & & \\
e pooled & 2.297 & 6 & 0.383 & &
\end{tabular}

SS Sum of squares, DOF Degree of freedom, $V$ Variance, $\mathrm{F}_{\text {calc }} \mathrm{F}$ value calculated in $F$ test, $\mathrm{P}$ $(\%)=\mathrm{SS}_{\mathrm{Tot}} / \mathrm{SS}_{\mathrm{i}}$ Percent contribution.

a Significant at $95 \%$ confidence level.
Table 5

Significant factors affecting Young's modulus in air and in PBS and their optimal values, among the two investigated values, in order of contribution.

\begin{tabular}{ll}
\hline Significant factors & Optimal level \\
\hline Young's modulus in air & \\
B: Mixing temperature & $190{ }^{\circ} \mathrm{C}$ \\
C: Mixing time & $300 \mathrm{~s}$ \\
D: Porogen salt & $\mathrm{NaCl}$ \\
A: Salt granulometry & $0-45 \mu \mathrm{m}$ \\
E: Leaching time & $5 \mathrm{~h}$ \\
Young's modulus in PBS & \\
B: Mixing temperature & $190{ }^{\circ} \mathrm{C}$ \\
C: Mixing time & $300 \mathrm{~s}$ \\
G: Leaching pH & $7 \mathrm{no} \mathrm{buffer}$ \\
E: Leaching time & $5 \mathrm{~h}$ \\
A: Salt granulometry & $0-45 \mu \mathrm{m}$ \\
D: Porogen salt & $\mathrm{NaCl}$ \\
\hline
\end{tabular}

and time of leaching. More in detail, the temperature and the time of mixing are the most statistically significant variable and theirs optimal level were the lowest (at 95\% confidence level). In particular, the highest elastic modulus value was obtained for the samples prepared by melt mixing temperature of $190^{\circ} \mathrm{C}$ and for a mixing time of $300 \mathrm{~s}$. Increasing one of these parameters induce a significant reduction of the modulus value in almost all the experiments. These results can be likely associated to the thermo-degradation of the polymer chains induced by the melt mixing.

In this work, the combination of Taguchi's experimental design and ANOVA provided a simple and effective systematic approach for the determination of the optimal levels of the significant parameters carrying out a reduced number of experiments.

The optimal values obtained in this research may be adopted in future process of fabrication of porous scaffolds within the melt mixing and particulate leaching with same materials. Moreover, this work may be considered as a preliminary study for further experimental investigation of the significant factors in more complicated factorial design or to evaluate further properties such as cell activities, adhesion, infiltration and differentiation, as well as control of cell delivery with drug impregnation in PLA scaffold and kinetic of bioabsorption.

\section{Appendix A. Supplementary data}

Supplementary data to this article can be found online at http://dx. doi.org/10.1016/j.matdes.2017.06.025.

\section{References}

[1] S.-S. Kim, M. Park, O. Jeon, C. Choi, B.-S. Kim, Poly(lactide-co-glycolide)/hydroxyapatite composite scaffolds for bone tissue engineering, Biomaterials 27 (2006) 1399-1409, http://dx.doi.org/10.1016/j.biomaterials.2005.08.016.

[2] Y. Ikada, Challenges in tissue engineering, J. R. Soc. Interface 3 (2006) 589-601.

[3] R. Scaffaro, F. Lopresti, A. Maio, F. Sutera, L. Botta, Development of polymeric functionally graded scaffold: a brief review, J. Appl. Biomater. Funct. Mater (2016) In press. 10.5301/jabfm.5000252.

[4] R. Scaffaro, F. Lopresti, L. Botta, S. Rigogliuso, G. Ghersi, Integration of PCL and PLA in a monolithic porous scaffold for interface tissue engineering, J. Mech. Behav. Biomed. Mater. 63 (2016) 303-313, http://dx.doi.org/10.1016/j.jmbbm.2016.06. 021.

[5] R. Scaffaro, F. Lopresti, L. Botta, A. Maio, Mechanical behavior of polylactic acid/ polycaprolactone porous layered functional composites, Compos. Part B Eng. 98 (2016) 70-77, http://dx.doi.org/10.1016/j.compositesb.2016.05.023.

[6] E. Eisenbarth, Biomaterials for tissue engineering, Adv. Eng. Mater. 9 (2007) 1051-1060, http://dx.doi.org/10.1002/adem.200700287.

[7] A.A. Chaudhari, K. Vig, D.R. Baganizi, R. Sahu, S. Dixit, V. Dennis, S.R. Singh, S.R. Pillai, Future prospects for scaffolding methods and biomaterials in skin tissue engineering: a review, Int. J. Mol. Sci. 17 (2016) 1974-2004.

[8] M. Flaibani, N. Elvassore, Gas anti-solvent precipitation assisted salt leaching for generation of micro- and nano-porous wall in bio-polymeric 3D scaffolds, Mater. Sci. Eng. C 32 (2012) 1631-1639, http://dx.doi.org/10.1016/j.msec.2012.04.054.

[9] R. Scaffaro, F. Lopresti, A. Maio, L. Botta, S. Rigogliuso, G. Ghersi, Electrospun PCL/GOg-PEG structures: processing-morphology-properties relationships, Compos. Part A 
Appl. Sci. Manuf. 92 (2017) 97-107, http://dx.doi.org/10.1016/j.compositesa.2016. 11.005 .

[10] R. Scaffaro, F. Lopresti, L. Botta, S. Rigogliuso, G. Ghersi, Melt processed PCL/PEG scaffold with discrete pore size gradient for selective cellular infiltration, Macromol. Mater. Eng. 301 (2016) 182-190, http://dx.doi.org/10.1002/mame.201500289.

[11] P. Gentile, V. Chiono, I. Carmagnola, P.V. Hatton, An overview of poly(lactic-coglycolic) acid (PLGA)-based biomaterials for bone tissue engineering, Int. J. Mol. Sci. 15 (2014) 3640-3659, http://dx.doi.org/10.3390/ijms15033640.

[12] M.S. Shoichet, Polymer scaffolds for biomaterials applications, Macromolecules 43 (2010) 581-591, http://dx.doi.org/10.1021/ma901530r.

[13] R. Scaffaro, F. Lopresti, L. Botta, S. Rigogliuso, G. Ghersi, Preparation of three-layered porous PLA/PEG scaffold: relationship between morphology, mechanical behavior and cell permeability, J. Mech. Behav. Biomed. Mater. 54 (2016) 8-20, http://dx. doi.org/10.1016/j.jmbbm.2015.08.033.

[14] R. Scaffaro, L. Botta, F. Lopresti, A. Maio, F. Sutera, Polysaccharide nanocrystals as fillers for PLA based nanocomposites, Cellulose 24 (2016) 447-478, http://dx.doi. org/10.1007/s10570-016-1143-3.

[15] T. Serra, M. Ortiz-Hernandez, E. Engel, J.A. Planell, M. Navarro, Relevance of PEG in PLA-based blends for tissue engineering 3D-printed scaffolds, Mater. Sci. Eng. C 38 (2014) 55-62.

[16] R. Scaffaro, A. Maio, F. Lopresti, D. Giallombardo, L. Botta, M.L. Bondì, S. Agnello, Synthesis and self-assembly of a PEGylated-graphene aerogel, Compos. Sci. Technol. 128 (2016) 193-200, http://dx.doi.org/10.1016/j.compscitech.2016.03.030.

[17] R. Scaffaro, F. Lopresti, A. Sutera, L. Botta, R.M. Fontana, A.M. Puglia, G. Gallo, Effect of PCL/PEG-based membranes on actinorhodin production in Streptomyces coelicolor cultivations, Macromol. Biosci. 16 (2016) 686-693, http://dx.doi.org/10.1002/ mabi.201500391.

[18] R. Scaffaro, F. Lopresti, L. Botta, A. Maio, F. Sutera, M.C. Mistretta, F.P. La Mantia, A facile and eco-friendly route to fabricate poly(lactic acid) scaffolds with graded pore size, J. Vis. Exp. (2016) 1-8, http://dx.doi.org/10.3791/54595.

[19] M.H. Casimiro, J.J.H. Lancastre, A.P. Rodrigues, S.R. Gomes, G. Rodrigues, L.M. Ferreira, Chitosan-based matrices prepared by gamma irradiation for tissue regeneration: structural properties vs. preparation method, Top. Curr. Chem. 375 (2017) $1-25$

[20] H. Janik, M. Marzec, A review: fabrication of porous polyurethane scaffolds, Mater. Sci. Eng. C 48 (2015) 586-591, http://dx.doi.org/10.1016/j.msec.2014.12.037.

[21] H.-Y. Mi, X. Jing, E. Yu, J. McNulty, X.-F. Peng, L.-S. Turng, Fabrication of triple-layered vascular scaffolds by combining electrospinning, braiding, and thermally induced phase separation, Mater. Lett. 161 (2015) 305-308, http://dx.doi.org/10.1016/j. matlet.2015.08.119.

[22] S. Columbus, L.K. Krishnan, V. Kalliyana Krishnan, Relating pore size variation of poly ( $\varepsilon$-caprolactone) scaffolds to molecular weight of porogen and evaluation of scaffold properties after degradation, J Biomed Mater Res B Appl Biomater 102 (2014) 789-796, http://dx.doi.org/10.1002/jbm.b.33060.

[23] J. Zhang, H.M. Yin, B.S. Hsiao, G.J. Zhong, Z.M. Li, Biodegradable poly(lactic acid)/hydroxyl apatite 3D porous scaffolds using high-pressure molding and salt leaching, J. Mater. Sci. 49 (2014) 1648-1658, http://dx.doi.org/10.1007/s10853-013-7848-x.

[24] J. Pu, F. Yuan, S. Li, K. Komvopoulos, Electrospun bilayer fibrous scaffolds for enhanced cell infiltration and vascularization in vivo, Acta Biomater. 13 (2015) 131-141, http://dx.doi.org/10.1016/j.actbio.2014.11.014.

[25] Y.J. Tan, W.Y. Yeong, X. Tan, J. An, K.S. Chian, K.F. Leong, Characterization, mechanical behavior and in vitro evaluation of a melt-drawn scaffold for esophageal tissue engineering, J. Mech. Behav. Biomed. Mater. 57 (2016) 246-259, http://dx.doi.org/10. 1016/j.jmbbm.2015.12.015.

[26] B. Yuan, Q.L. Yu, H.J.H. Brouwers, Reaction kinetics, reaction products and compressive strength of ternary activators activated slag designed by Taguchi method, Mater. Des. 86 (2015) 878-886, http://dx.doi.org/10.1016/j.matdes.2015.07.077.

[27] J.V. Esteves, S.M. Goushegir, J.F. dos Santos, L.B. Canto, E. Hage, S.T. Amancio-Filho, Friction spot joining of aluminum AA6181-T4 and carbon fiber-reinforced poly(phenylene sulfide): effects of process parameters on the microstructure and mechanical strength, Mater. Des. 66 (2015) 437-445, http://dx.doi.org/10.1016/j. matdes.2014.06.070.

[28] C.W. Chan, G.C. Smith, Fibre laser joining of highly dissimilar materials: commercially pure Ti and PET hybrid joint for medical device applications, Mater. Des. 103 (2016) 278-292, http://dx.doi.org/10.1016/j.matdes.2016.04.086.

[29] Y.T. Chung, M.M. Ba-Abbad, A.W. Mohammad, N.H.H. Hairom, A. Benamor, Synthesis of minimal-size $\mathrm{ZnO}$ nanoparticles through sol-gel method: Taguchi design optimisation, Mater. Des. 87 (2015) 780-787, http://dx.doi.org/10.1016/j.matdes.2015.07. 040.

[30] M.S. Senthil Kumar, N. Mohana Sundara Raju, P.S. Sampath, U. Vivek, Tribological analysis of nano clay/epoxy/glass fiber by using Taguchi's technique, Mater. Des. 70 (2015) 1-9, http://dx.doi.org/10.1016/j.matdes.2014.12.033.

[31] S.R. Rao, G. Padmanabhan, Application of Taguchi methods and ANOVA in optimization of process parameters for metal removal rate in electrochemical machining of Al/5\% SiC composites, Int. J. Eng. Res. Appl. 2 (2012) 192-197.
[32] N.M. Mehat, S. Kamaruddin, Optimization of mechanical properties of recycled plastic products via optimal processing parameters using the Taguchi method, J. Mater. Process. Technol. 211 (2011) 1989-1994, http://dx.doi.org/10.1016/j.jmatprotec. 2011.06.014.

[33] B. Ozcelik, T. Erzurumlu, Comparison of the warpage optimization in the plastic injection molding using ANOVA, neural network model and genetic algorithm, J. Mater. Process. Technol. 171 (2006) 437-445, http://dx.doi.org/10.1016/j. jmatprotec.2005.04.120.

[34] A.G. Thakur, V.M. Nandedkar, Application of Taguchi method to determine resistance spot welding condition of austenitic stainless steel AISI 304, Delta. 1 (2010) $3-43$.

[35] B.M. Gopalsamy, B. Mondal, S. Ghosh, Taguchi method and anova: an approach for process parameters optimization of hard machining while machining hardened steel, J. Sci. Ind. Res. (India). 68 (2009) 686-695.

[36] M. Emami, M.H. Sadeghi, A.A.D. Sarhan, F. Hasani, Investigating the minimum quantity lubrication in grinding of Al 203 engineering ceramic, J. Clean. Prod. 66 (2014) 632-643, http://dx.doi.org/10.1016/j.jclepro.2013.11.018.

[37] R.S. Jadoun, P. Kumar, B.K. Mishra, Taguchi's optimization of process parameters for production accuracy in ultrasonic drilling of engineering ceramics, Prod. Eng. 3 (2009) 243-253, http://dx.doi.org/10.1007/s11740-009-0164-2.

[38] E.Y.K. Ng, W.K. Ng, Parametric study of the biopotential equation for breast tumour identification using ANOVA and Taguchi method, Med. Biol. Eng. Comput. 44 (2006) 131-139, http://dx.doi.org/10.1007/s11517-005-0006-0.

[39] H.C. Lin, C.T. Su, C.C. Wang, B.H. Chang, R.C. Juang, Parameter optimization of continuous sputtering process based on Taguchi methods, neural networks, desirability function, and genetic algorithms, Expert Syst. Appl. 39 (2012) 12918-12925, http://dx.doi.org/10.1016/j.eswa.2012.05.032.

[40] F.H. Dar, J.R. Meakin, R.M. Aspden, Statistical methods in finite element analysis, J. Biomech. 35 (2002) 1155-1161.

[41] S. Vigneswari, H.P.S. Abdul Khalil, A.A. Amirul, Designing of collagen based poly(3hydroxybutyrate- co-4-hydroxybutyrate) scaffolds for tissue engineering, Int. J. Polym. Sci. 2015 (2015) 1-10, http://dx.doi.org/10.1155/2015/731690.

[42] R.K. Roy, Design of Experiments Using the Taguchi Approach: 16 Steps to Product and Process Improvement, John Wiley \& Sons, 2001.

[43] R. Muthuraj, M. Misra, F. Defersha, A.K. Mohanty, Influence of processing parameters on the impact strength of biocomposites: a statistical approach, Compos. Part A Appl. Sci. Manuf. 83 (2016) 120-129.

[44] J. Lam, K. Kim, S. Lu, Y. Tabata, D.W. Scott, A.G. Mikos, F. Kurtis Kasper, A factorial analysis of the combined effects of hydrogel fabrication parameters on the in vitro swelling and degradation of oligo (poly (ethylene glycol) fumarate) hydrogels, J. Biomed. Mater. Res. Part A. 102 (2014) 3477-3487.

[45] D.C. Montgomery, Introduction to factorial designs, Des. Anal. Exp. (2005) 160-197.

[46] P.J. Ross, Taguchi Techniques for Quality Engineering: Loss Function, Orthogonal Experiments, Parameter and Tolerance Design, 1996.

[47] R.K. Roy, A Primer on the Taguchi Method, Society of Manufacturing Engineers, 2010.

[48] M. Puchalski, S. Kwolek, G. Szparaga, M. Chrzanowski, I. Krucińska, Investigation of the influence of PLA molecular structure on the crystalline forms $\left(\alpha^{\prime}\right.$ and $\left.\alpha\right)$ and mechanical properties of wet spinning fibres, Polymers (Basel) 9 (2017) 8, http:// dx.doi.org/10.3390/polym9010018.

[49] G. Lo Re, F. Lopresti, G. Petrucci, R. Scaffaro, A facile method to determine pore size distribution in porous scaffold by using image processing, Micron 76 (2015) 37-45, http://dx.doi.org/10.1016/j.micron.2015.05.001.

[50] M. Fan, G. Guo, S. Shi, X. Wang, S. Fu, X. Li, X. Tang, P. Xie, Z. Qian, F. Luo, Preparation and characterization of porous scaffold based on poly (lactic acid) and poly (ethylene glycol) by phase separation method, Adv. Sci. Lett. 11 (2012) 80-85.

[51] J.E. Goodrich, R.S. Porter, A rheological interpretation of torque-rheometer data Polym. Eng. Sci. 7 (1967) 45-51, http://dx.doi.org/10.1002/pen.760070112.

[52] K. Hamad, M. Kaseem, F. Deri, Melt rheology of poly(lactic acid)/low density polyethylene polymer blends, Adv. Chem. Eng. Sci. 1 (2011) 208-214, http://dx.doi. org/10.4236/aces.2011.14030.

[53] J.-E. Park, M. Todo, Development and characterization of reinforced poly(L-lactide) scaffolds for bone tissue engineering, J. Mater. Sci. Mater. Med. 22 (2011) $1171-1182$.

[54] N.S.Q.S. Amorin, G. Rosa, J.F. Alves, S.P.C. Gonçalves, S.M.M. Franchetti, G.J.M. Fechine, Study of thermodegradation and thermostabilization of poly(lactide acid) using subsequent extrusion cycles, J. Appl. Polym. Sci. 131 (2014) 1-8, http://dx. doi.org/10.1002/app.40023.

[55] X. Gong, C.Y. Tang, Y. Zhang, C.T. Wong, S. Wu, J. Liu, Fabrication of graded macroporous poly (lactic acid) scaffold by a progressive solvent casting/porogen leaching approach, J. Appl. Polym. Sci. 125 (2012) 571-577. 